\title{
PRIMJENA BIM-A I SRODNIH TEHNOLOGIJA U PROCESU INDUSTRIJALIZACIJE U GRAĐEVINARSTVU
}

\section{IMPLEMENTATION OF BIM AND RELATED TECHNOLOGIES IN THE PROCESS OF INDUSTRIALIZATION OF CONSTRUCTION}

\author{
Mirjana Terzić, Fakultet tehničkih nauka, Novi Sad
}

\section{Oblast - GRAĐEVINARSTVO}

Kratak sadržaj - Industrijalizacija građenja se postiže projektovanjem odgovarajućih tehničkih rješenja objekata primjenom $i$ ovladavanjem savremenom tehnologijom, kvalitetnim planiranjem i organizacijom procesa. Danas građevinska industrija prihvata nove digitalne alate kao što su $3 D$ modeliranje, informaciono modeliranje zgrada - BIM (Building Information Modeling), IoT (Internet of Things) i njima srodne tehnologije.

Ključne reči: Industrijalizacija, AEC industrija, BIM, Građevinski otpad, Lean izgradnja

Abstract - Industrialization of construction is achieved by designing appropriate technical solutions for buildings by applying and mastering modern technologies, quality process of planning and organization. Today, the construction industry is embracing new digital tools such as 3D modeling, Building information modeling - BIM, Internet of Things - IoT and other related technologies.

Keywords: Industrialization, AEC industry, BIM, Lean, Construction waste

\section{UVOD}

Industrijalizacija u građevinarstvu se još uvijek kreće sporijom uzlaznom putanjom uprkos ogromnom potencijalu da da rješenja za većinu aktuelnih problema sa kojim se AEC industrija (Architecture, Engineering, and Construction) suočava. AEC industrija sastoji se od arhitekture, inženjerstva i građevinarstva - koji rade zajedno kako bi se neki projekat ostvario. Njihovom integracijom $u$ jednu industriju, arhitekte, inženjeri $i$ izvođači mogu učinkovitije i praktičnije raditi na postizanju zajedničkog cilja. Činjenica da tri različite, ali srodne industrije čine jedan sistem, koji zajedno djeluje, komplikuje industrijske standarde koji ih definišu, jer svaka komponenta procesa izgradnje pojedinačno pokriva široku oblast. AEC industrija stavlja snažan naglasak na praćenje najnovije tehnologije koja olakšava razmjenu informacija. Budući da krajnji kupac obično direktno komunicira s barem jednim njenim aspektom, razmjena informacija između arhitekti, inženjera i izvođača radova postaje veoma bitna.

Najčešći problemi na projektu vezani za sam kvalitet učesnika ili ključnih procesa u preduzećima su sledeći:

\section{NAPOMENA:}

Ovaj rad proistekao je iz master rada čiji mentor je bio dr Igor Peško, vanr. prof.
- Prekoračenje roka;

- Nekvalitetan konačan proizvod ili neadekvatni ugrađeni materijali;

- Neprecizno vođenje knjiga i upravljanje projektom;

- Pogrešno procjenjeni troškovi;

- Netačni predmjeri radova;

- Loša faza planiranja i pripreme projekta;

- Nedostatak standardizacije u pojedinim oblastima;

\section{INDUSTRIJALIZACIJA}

Industrijalizacija u građevinarstvu predstavlja napredovanje građevinskih procesa primjenom mehanizacije i automatizacije, odnosno sistem koji koristi inovativnije i integrisanije tehnike za sve etape građevinskog projekta. Industrijalizacija je značajan trend u slopu naučno-tehnološkog napretka u građevinarstvu, kao tehnologija koja mijenja način na koji projektujemo, proizvodimo i montiramo. Sa ovim novim pristupom težnja je da grane AEC industrije budu usklađene tako da proizvode visoko kvalifikovane radnike, obučene za digitalno doba i sve promjene koje se očekuju.

Industrijalizacija rezultuje preciznijim i ujednačenijim kvalitetom proizvoda. Kombinovanjem automatizacije sa BIM modelom, virtualnom stvarnošću ili sa „Internet of Things“ objekat se može posmatrati u realnom okruženju prije procesa građenja, ili pak u realnom vremenu u toku procesa građenja, što dovodi do blagovremenog reagovanja i smanjenja grešaka. Upravo to omogućava bolju kontrolu kvaliteta nego što bi to bio slučaj na gradilištu.

Uvođenje automatizacije smanjuje kašnjenja na projektu i trajanja pojedinačnih aktivnosti. Kombinovanjem sa robotikom rad se može obavljati u više radnih sati danju i noću, na primjer u dvije ili tri smjene. Sve to povećava šanse da se projekat završi na projektovano vrijeme. Prefabrikacija smanjuje potrebu za koordinacijom između različitih grupa učesnika na projektu, a sa većinom posla obavljenim u fabrici smanjuju se kašnjenja uzrokovana lošim vremenskim prilikama na gradilištu.

Sledeća korist se ogleda u bezbjednosti i zdravlju na radu, jer je samo gradilište opasno mjesto na kojem su radnici svakodnevno izloženi nekom riziku. $\mathrm{Na}$ primjer, rad na visini, loše vremenske prilike, rad sa opasnim materijalima ili električnom strujom - mogu biti zamjenjene kontrolisanim fabričkim okruženjem i procesom prefabrikacije.

Industrijska revolucija 4.0 je dala izazov za građevinsku industriju pružajući uvid u potencijal digitalizacije građevinskih objekata, uz dostupnost digitalnih podataka i online digitalnog pristupa koji automatski prikupljaju i 
obrađuju elektronske podatke. Ako bi se pregledao koncept Industrijske revolucije $4.0 \mathrm{u}$ građevinskoj industriji u poslednjih pet godina, može se uočiti aktivna saradnja između BIM-a sa tehnologijama iz industrije 4.0, ali takođe i njihov sam napredak (vještačka inteligencija, mašinsko učenje, robotika, 3D štampanje i druge), slika 1.

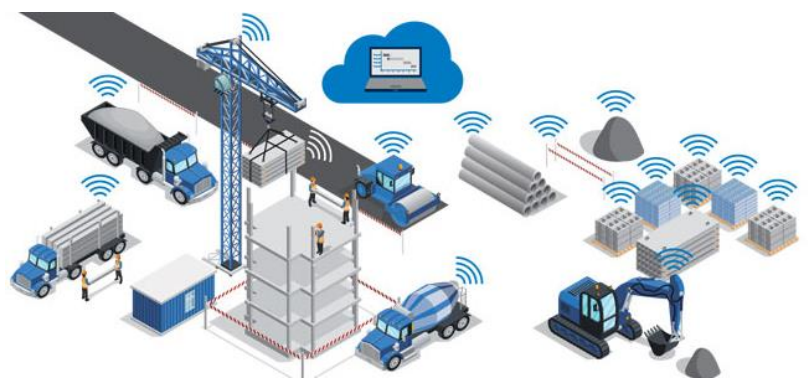

Slika 1. Digitalizacija gradilišta [1]

\subsection{Prefabrikacija}

Prefabrikacija je izrada montažnih prefabrikovanih konstrukcija, čiji elementi se proizvode van mjesta na kom će se nalaziti u konstrukciji, a nakon očvršćavanja se ugrađuju - montiraju u projektovani položaj. Primjenom prefabrikacije sa jedne i BIM softvera sa druge strane ispunjavamo osnovne principe procesa industrijalizacije. Niz tehničkih i tehnoloških mjera i metoda su primjenjene sa ciljem da se proces projektovanja i proizvodnje optimizuje, ubrza i olakša. Takođe da se izvrši racionalizacija utroška resursa $i$ da se automatizuju sve aktivnosti koje se često ponavljaju.

\subsection{Virtualna stvarnost}

Virtualna stvarnost (Virtual Reality) je skup tehnologija koje se koriste za sintezu sklopa vizuelnih, zvučnih, dodirnih, a ponekad i drugih čula. U današnje vrijeme se intenzivno koristi u građevinarstvu i njoj srodnim disciplinama, gdje korisnici imaju mogućnost da putem virtuelnog obilaska stambenog objekta koji jos nije izgrađen, izaberu nekretninu koju će kupiti ili sugerišu projektantima željene izmjene.

\subsection{Robotika}

Koncept robota ili potrebe za mašinom koja će zamjeniti ili ubrzati ljudski rad pominje se još u antičkom periodu i srednjem vijeku, međutim tek nakon industrijske revolucije i ubrzanog tehnološkog razvoja robotika doživljava svoj razvoj. Roboti su igrali ključnu ulogu u automatizaciji industrijske proizvodnje, dok sa druge strane u AEC industriji nije toliko jednostavno definisati šta je to robot. Uglavnom jer se ovaj termin koristi najčešće za robotske ruke, preprogramirane $\mathrm{CNC}$ rezače $\mathrm{i}$ 3D štampače - suštinski sve mašine sa unijetim parametrima koji olakšavaju digitalnu proizvodnju i štede na vremenu i novčanim sredstvima.

\subsection{D štampanje}

Građevinsko 3D štampanje odnosi se na različite tehnologije koje koriste 3D štampu kao osnovni metod za proizvodnju zgrada ili građevinskih elemenata. Postoje razne metode 3D štampe koje se koriste u građevinskim oblastima, a glavne su ekstruzija, vezivanje prahom i aditivno zavarivanje. 3D štampanje betonom, kombinovano s prefabrikacionim metodama, ima potencijal da smanji vrijeme potrebno za izvođenje kompleksnih elemenata $\mathrm{s}$ nekoliko nedelja na nekoliko dana. Ova tehnologija će posebno pomoći u gradnji nepravilnih i zaobljenih formi koji se dosta teško izvode konvencionalnim metodama.

\subsection{Internet of Things}

U građevinarstvu, IoT može da pomogne u rešavanju brojnih problema. $\mathrm{Na}$ primjer, zahvaljujući raznim senzorima na gradilištu, upravljanje projektima postaje efikasnije a proces izgradnje postaje sigurniji i optimizovaniji. Senzori prikupljaju podatke na gradilištu, zatim se obrađuju softverom i daju menadžeru projekta potpunu sliku radne situacije. Ova tehnologija pomaže u kontroli velikih projekata, smanjujući vrijeme i troškove nadgledanja zadataka. Podaci se prikupljaju automatski i daje se sažetak, a informacije jasno pokazuju kada je potrebno preventivno održavanje, zamjena ili popravke, slika 2.

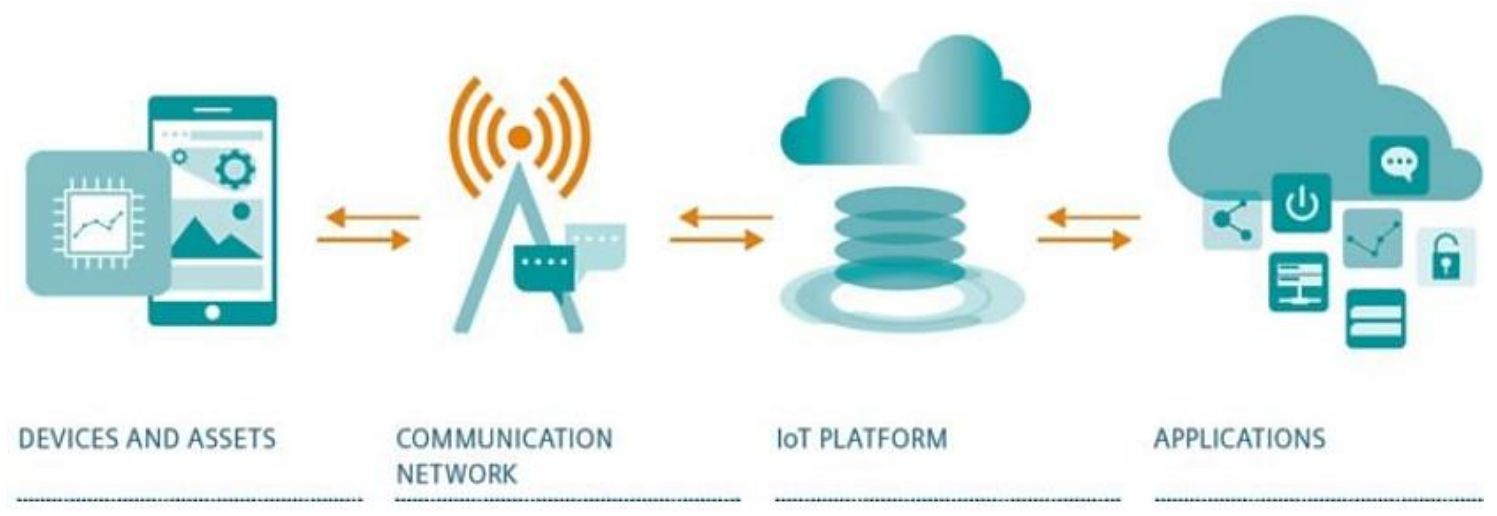

Slika 2. Hronološko osmišljavanje primjene Internet of Things [2]

\section{BIM}

Globalni trendovi postavljaju nove izazove i zahtjeve, što dovodi do pojave sve više kompleksnih projekata u AEC industriji. Konstantan napredak tehnologija u građevinskoj industriji zahtjeva veću efikasnost i bolje rezultate.
Era optimizacije čitavog procesa izgradnje - u pogledu kvaliteta, vremena i troškova počela je pojavom CAD (Computer-aided design) softvera za projektovanje, izgradnju i upravljanje projektima. 
Sami počeci su bili zasnovani na konceptu stvaranja i prikaza dvodimenzionalnih i trodimenzionalnih modela. Dalji napredak se ogleda u stvaranju virtuelnih modela zgrada kao temelj samog BIM-a, a danas se razvijaju inovativna rješenja kako za inženjere, tako i za investitore i izvođače.

Informaciono modeliranje zgrada predstavlja novi pristup dizajnu, statičkoj analizi, proračunu vremena i troškova i upravljanju zgradama tokom cijelog njenog životnog vijeka. BIM je pristup koji se može posmatrati kao tehnologija i kao metodologija. Kao ,tehnologija“ predstavlja digitalnu reprezentaciju fizičkih i funkcionalnih karakteristika objekta, a kao „metodologija“ omogućava saradnju različitih učesnika u različitim fazama životnog vijeka objekta, slika 3 .

Ako se koristi na adekvatan i optimalan način, BIM način rada pruža priliku za poboljšanje tradicionalnih metoda projektovanja i procesa građenja, čime se smanjuju mogućnosti skupih promjena na projektu i otvaraju se mnoge druge mogućnosti za racionalizaciju procesa.
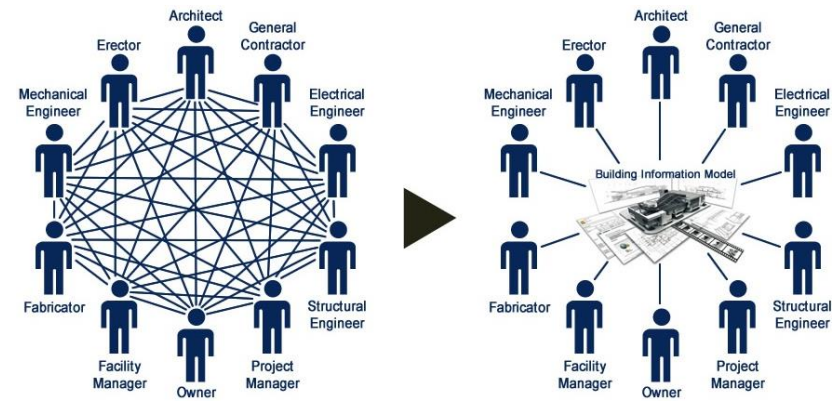

Slika 3. Razmjena informacija i dokumenata u $2 D$ projektu i BIM projektu [3]

BIM pristup primjenjuje se u svim životnim fazama projekta - planiranju, projektovanju, građenju, upravljanju objektima i njihovim održavanjem, te samim tim omogućuva:

- Podršku u projektnim procesima donošenja odluka;

- Rano uočavanje potencijalnih grešaka na projektu;

- Detaljne analize;

- Brze izmjene i lakše upravljanje revizijama;

- Jasnije razumijevanje projektnih ciljeva i odnosa s drugim učesnicima na projektu;

- Vizualizaciju projektnih rješenja;

- Poboljšanja u projektovanju i koordinaciji projekata;

- Povećanje i osiguravanje kvaliteta građevinskih procesa i konačnog proizvoda;

- Učinkovitost procesa u fazi građenja;

- Povećanje sigurnosti u fazi građenja, ali i tokom ostalih životnih faza objekta;

- Podršku u analizi životnog ciklusa i troškova projekta;

\subsection{BIM model}

3D model objekata omogućava projektantima i učesnicima projekta da steknu utisak o dizajnu, obliku i gabaritima nekog objekta. Za razliku od BIM modela, 3D model ne prikazuje detalje. Modeliranje informacija o zgradama je metod koji izrađuje digitalni model zgrade koji može poslužiti projektantima različitih struka kao temelj za rad. Ovaj BIM model prati projektante od izgradnje do same upotrebe objekta. Dakle, ovde više nije reč o posebnim radnim koracima i fazama koje su odvojene cjeline već se u ovom modelu sve faze odvijaju na istim temeljima.

Revizije projekta, naročito u tradicionalnom načinu rada, mogu da uzrokuju velike greške i još veća kašnjenja.

Primjenom BIM softvera i načina razmišljanja proces revizija je znatno pojednostavljen. Nedostaci u projektu se brže detektuju i lakše saniraju, naravno ukoliko je tok informacija dobro struktuiran. Na dalje svaka izmjena se automatski ažurira između učesnika u BIM modelu, kao i svi izvještaji i specifikacije, a prilikom unošenja te izmjene na $3 \mathrm{D}$ prikazu je lakše uočiti na šta sve promjena utiče, slika 4.

Da bi se što manje problema pojavilo u fazi izvođenja, potrebna je velika preciznost $u$ fazi projektovanja što nam primjena BIM softvera i omogućava. Primjer toga je i analiza sudara u 3D modelu za konstruktivne ili nekonstruktivne elemente, armaturu, ugrađena pomoćna sredstva, instalacije itd. Uz pomoć ovog alata se mogu na vrijeme otkriti sve kolizije, ispraviti i osigurati neometan proces izvođenja. Na slici 4. su prikazana mjesta kolizije šipki armature i uzengija unutar složenijeg betonskog elementa.

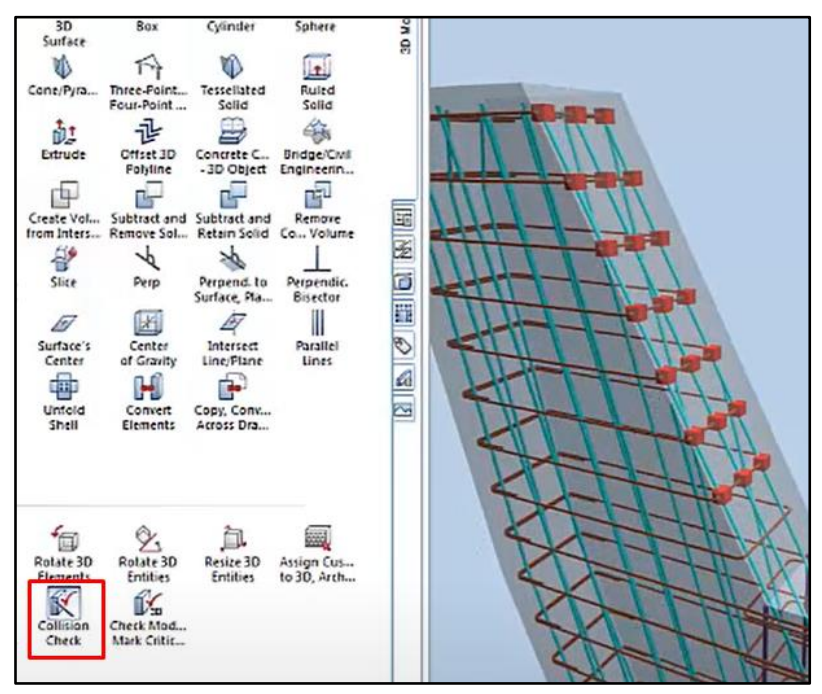

Slika 4. Primjer provjere kolizije armature u betonskom elementu, u BIM softveru Allplan

Kako bi se iz BIM softvera izvukao kvalitetan predmjer radova, treba voditi računa da ne dođe do preklapanja zapremina i površina dva ili više elemenata, da ne bi došlo do dupliranja količina u predmjeru. Zahvaljujući tome na veoma lak $\mathrm{i}$ brz način se mogu predvijeti potrebne količine radova kao i definisati okvirni troškovi. Greške prilikom loše procjene u procesu projektovanja kasnije u toku građenja skoro uvijek dovode do vremenskih zastoja i ekonomskih gubitaka.

\subsection{BIM softveri}

Iako BIM jeste pristup a ne softver, njegova primjena uveliko zavisi od upotrebe odgovarajućih softverskih rješenja. BIM softver mora imati mogućnost prezentovanja fizičkih i funkcionalnih svojstava objekta kao modela na koji se veže baza podataka.

Osnovne praktične prednosti BIM softverskih paketa su:

- Dodavanje i automatsko povezivanje ključnih informacija (specifikacija materijala, položaj detalja, 
predmjer količina potrebnih za naručivanje materijala i analizu troškova);

- Detaljna vizualizacija 3D modela;

- Mogućnost automatizacije i standardizacije elemenata;

- Kontinuirano sagledavanje svih potrebnih informacija, precizno praćenje projekta kao cjeline, i vremenska ušteda prilikom revizija, promjena, kontrole i praćenja projekta;

- Automatsko ažuriranje unešenih promjena kako u svim presjecima i osnovama, tako i u svim izvještajima i specifikacijama;

- Tačnija dokumentacija sa minimalnim greškama i uočavanje kolizija ugrađenih elemenata;

- Timski rad i lakši protok informacija;

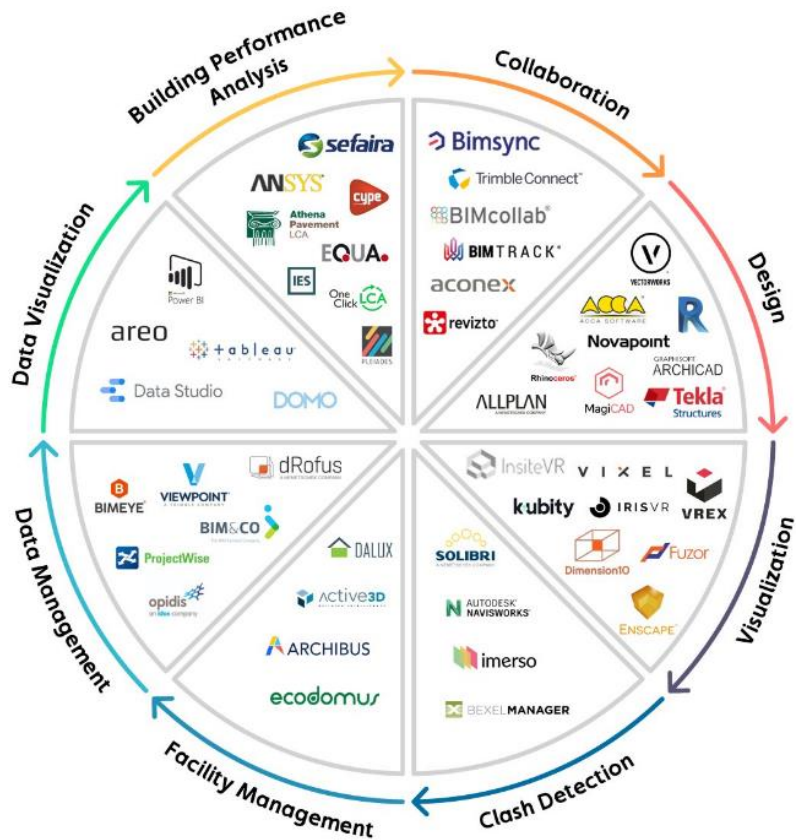

Slika 5. Mapa BIM softvera sortiranih prema glavnoj namjeni [4]

Implementacija industrijalizacije u kompanijama na razne načine optimizuje svakodnevni rad i procese građevinskog projekta. Samo jedan od brojih primjera jeste uvođenje standardizacije elemenata zarad lakšeg projektovanja, bržeg izvođenja i smanjenja grešaka. U ,biblioteci“ većine softvera postoje i gotovi standardni elementi kao što su konstrukcija stepeništa, grede, vrata, prozori, sklop armature, čelični profili, termoizolacija,opekarski proizvodi itd. Oni mogu biti ubačeni u projekat samo jednim klikom, što znatno ubrzava proces projektovanja naspram tradicionalnog načina.

\section{MINIMIZIRANJE GRAĐEVINSKOG OTPADA}

Dugo godina je bio izazov obezbjediti tehnike i alate koji će identifikovati uzrok i rješiti problem građevinskog otpada. Osnova za takav pristup je između ostalog i Informaciono modeliranje zgrada - BIM i njemu srodne tehnologije, kako bi se procjenilo i sagledalo stvaranje otpada kroz cijeli životni vijek objekta. Iako metode projektovanja BIM-a nisu trenutno u potpunosti $u$ upotrebi, smatra se da bi njegovo usvajanje obuhvatilo ne samo cijeli životni ciklus zgrade, nego i uticaj izgradnje na ekološke principe i standarde.

\section{LEAN IZGRADNJA}

Lean izgradnja i razmišljanje prestavljaju način planiranja koji se koristi za opisivanje upravljačkih alata fokusiranih na identifikaciju i eliminaciju otpada, kontinualno poboljšanje proizvodnje, razumjevanje procesa i interakcije ljudi. Upravljanje građevinskim procesima ima ključnu ulogu u upravljanju troškovima, u identifikaciji i eliminisanju otpada te praćenju i kontroli realizacije projekta. Navedeni benefiti imaju direktan uticaj na povećanje produktivnosti procesa rada.

Dvije glavne metodologije su BIM i upotreba Lean principa sa njemu srodnim dijelom konstrukcijskog menadžmenta - LPS (Last Planner System).

\section{ZAKLJUČAK}

Niz tehničkih, i tehnoloških mjera i metoda se svakodnevno promoviše sa ciljem da se proces projektovanja $i$ proizvodnje optimizuje, ubrza i olakša. Takođe da se izvrši racionalizacija utroška resursa $i$ da se automatizuju sve aktivnosti koje se često ponavljaju. Informaciono modeliranje zgrada - BIM je tehnologija koja omogućava kreiranje višedimenzionalnog modela građevinskog objekta, koji će sadržiti sve informacije o njemu. Ovaj model će se koristiti ne samo za izgradnju, već i za eksploataciju objekta, kako bi se izbjegle prerade u dizajnu, smanjili troškovi izgradnje i što je najvažnije - uštedilo vrijeme. Iako uvođenje ove tehnologije zahtjeva finansijske troškove (kupovina softvera i opreme za obuku), ti troškovi se u budućnosti kompenziraju smanjenjem troškova projektovanja i organizovanja izgradnje.

\section{LITERATURA}

[1] https://www.tum.de/en/ Technical University of Munich (septembar 2021)

[2] https://www.siemens.com/global/en.html - Siemens (septembar 2021)

[3] https://www.dtu.dk/english - Technical University of Denmark (septembar 2021)

[4] https://catenda.com/fr/ - Catenda (septembar 2021)

\section{Kratka biografija:}

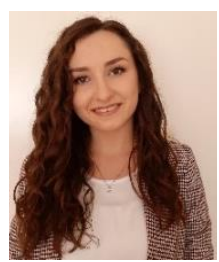

Mirjana Terzić rođena je u Vogošći 1994. god. Master rad na Fakultetu tehničkih nauka iz oblasti Građevinarstva - "Primjena BIM-a i srodnih tehnologija u procesu industrijalizacije u građevinarstvu" odbranila je 2021.god.

kontakt: mirjanaterzic94@gmail.com 